\title{
Genetics and Epigenetics of Diabetic Nephropathy
}

\author{
Ruijie Liua, ${ }^{a}$ Kyung Lee ${ }^{a}$ John Cijiang He $e^{a, b}$ \\ a Division of Nephrology, Department of Medicine, Icahn School of Medicine at Mount Sinai, and \\ ${ }^{\mathrm{b}}$ Renal Section, James J. Peters VAMC, New York, N.Y., USA
}

\section{Key Words}

Genetics · Epigenetics · Diabetic nephropathy · End-stage renal disease

\begin{abstract}
Background: Diabetic nephropathy (DN) is the most common cause of end-stage renal disease (ESRD) in the USA and worldwide, contributing to significant morbidity and mortality in diabetic patients. A genetic factor for the development of DN is strongly implicated, as only one third of diabetic patients eventually develop kidney disease. Growing evidence also supports an important role of epigenetic modifications in DN. Summary: Multiple studies have been performed to identify risk genes and loci associated with DN. So far, only several genes and loci have been identified, none of which showed a strong association with DN. Therefore, a better study design with a larger sample size to identify rare variants and a clinically defined patient population to identify genes and loci associated with progressive DN are still needed. In addition to genetic factors, epigenetic modifications, such as DNA methylation, histone modifications and microRNAs, also play a major role in the pathogenesis of DN through a second layer of gene regulation. Although a major progress has been made in this field, epigenetic studies in
\end{abstract}

DN are still in the early phase and have been limited mostly due to the heterogeneity of kidney tissue samples with multiple cells. However, rapid development of high-throughput genome-wide techniques will help us to better identify genetic variants and epigenetic changes in DN. Key Message: Understanding of genetic and epigenetic changes in DN is needed for the development of new biomarkers and better drug targets against DN. Summarized in this review are important recent findings on genetic and epigenetic studies in the field of DN.

c) 2015 S. Karger AG, Basel

\section{Introduction}

Diabetic nephropathy (DN), a devastating complication of diabetes, develops in $30-40 \%$ of patients with both type 1 and 2 diabetes [1]. DN is the leading cause of endstage kidney disease (ESRD) worldwide and in the USA. $\mathrm{DN}$ is clinically defined by the persistent microalbuminuria and gradual decline of kidney function that eventually leads to ESRD. The current treatment strategy of DN, including strict control of blood glucose, blood pressure, and renin-angiotensin system blockade, may slow down but not arrest the progression of $\mathrm{DN}$.

\section{KARGER 125}

C 2015 S. Karger AG, Basel

2296-9381/15/0011-0042\$39.50/0

E-Mail karger@karger.com

www.karger.com/kdd
John Cijiang He, MD

Division of Nephrology, Department of Medicine

Icahn School of Medicine at Mount Sinai, Box 1243

1 Gustave L. Levy Place, New York, NY 10029 (USA)

E-Mail cijiang.he@mssm.edu 
The etiology of DN is multifactorial, including genetic and environmental factors. The role of genetic susceptibility in the development of DN is evidenced by family aggregation [2] and the fact that not all patients with diabetes develop clinically evident DN despite long-term poor glycemic control. Identifying susceptible genetic loci or genes is apparently approach to dissect the mechanisms of onset and progression of DN. Therefore, many efforts have been made to identify genetic associations with DN using a variety of ways, including candidate gene screening, linkage analysis and genome-wide association studies (GWAS). GWAS is an unbiased and hypothesisfree approach to scan for a 'common variant', usually hundreds of thousands of single-nucleotide polymorphisms (SNPs) across the whole genome, in order to identify the disproportionately enriched SNPs in diabetic patients with nephrology. Genetic studies that analyzed DN of different kindred have generated a list of associated loci or genes. These associated loci or genes greatly broaden our understanding of the pathogenesis of DN. However, most of the genetic studies in the field of DN are inconsistent with an odds ratio $(\mathrm{OR})<2$. Likely, these loci or genes are unable to account for a significant proportion of heritability of DN, indicating the existence of factors beyond genetic sequence variations.

Epigenetics has been a rapidly evolving field in the past decade. Epigenetic regulation of gene expression is not related to alterations in primary nucleotide sequence of genes but to alternations in gene expressions through regulatory mechanisms that include DNA methylation, histone modifications (methylation, acetylation, phosphorylation, etc.), and expression of noncoding RNAs such as microRNAs (miRNAs). Methylation is considered to be chemically stable in the post-development stages, while other posttranslational modifications (PTMs) are potentially reversible. Some of these modification processes utilize metabolic intermediates such as reaction substrates or cofactors. For example, methylation transfers a methyl group from S-adenosyl methionine (SAM), a product of essential amino acid methionine metabolism, to DNA or histones. Acetylation, a covalent acetyl group addition to lysine residues of histone, is catalyzed by histone acetyltransferases that use acetyl-CoA as a substrate, and the Sirt family of histone deacetylases (HDACs) uses $\mathrm{NAD}^{+}$as a cofactor. Thus, the metabolic status may affect epigenetic modifications through changing the concentration of the metabolic intermediates. Diabetes is a disorder of several critical metabolic pathways. Therefore, the role of epigenetic modification induced by diabetes in $\mathrm{DN}$ is intriguing. In fact, accumulating evidence demon-
Table 1. Genetic variants identified by GWAS

\begin{tabular}{lll}
\hline Candidate gene & Ethnicity & Reference \\
\hline Type I & & \\
FRMD3 & EA & 3 \\
CARS & EA & 3 \\
ZMIZ1 & EA & 6 \\
ERBB4 & Multiple & 7 \\
AFF3 & Multiple & 7 \\
RGMA & Multiple & 7 \\
SORBS1 & Multiple & 8 \\
SP3 & Multiple & 9 \\
Type II & & \\
ELMO1 & Japanese & 11 \\
PVT1 & Pima Indian & 14 \\
MYH9 & AA & 18 \\
APOL1 & AA & 18 \\
LIMK2 & AA & 18 \\
SFI1 & AA & 18 \\
\hline
\end{tabular}

strates the important role of epigenetic modifications in DN. Likely, the interactive effects of genetics with epigenetics contribute to the development of DN. This review summarizes the current findings on the genetic variants and epigenetic modifications in DN.

\section{Genetics}

\section{Type 1 Diabetes}

Summarized here are the genetic variants identified from genome-wide screening studies and large-scale meta-analyses (table 1).

FRMD3/CARS: The Genetics of Kidney in diabetes (GoKinD) study [3] conducted a genome-wide SNP screening in patients with type 1 diabetes mellitus (T1DM) of European American (EA) descent with $(n=820)$ or without $(\mathrm{n}=855)$ kidney diseases to identify risk SNPs for DN. The SNPs that show the strongest association with $\mathrm{DN}$ and have successful replication in the Diabetes Control and Complications Trial (DCCT) are rs1888747 $\left(\mathrm{OR}=1.45, \mathrm{p}=5.0 \times 10^{-7}\right)$, located in the extended promoter region of FRMD3 (FERM domain-containing 3), and $\mathrm{rs} 451041\left(\mathrm{OR}=1.36, \mathrm{p}<3.1 \times 10^{-6}\right)$, located in an intronic region of CARS (cysteinyl-tRNA synthetase). FRMD3 was subsequently demonstrated to be associated with DN in type 2 diabetic Japanese [4] and EA patients [5]. CARS association with DN was also replicated in EA patients with type $2 \mathrm{DM}$ (T2DM) [5]. 
ZMIZ1: In a GWAS, Craig et al. [6] analyzed 555,352 SNPs of pooled DNA from Caucasian patients who had previously participated in the GoKinD study. They first identified 2,870 SNPs showed substantial differences in mean allele frequency, and then selected 22 highly ranked markers in patients with or without ESRD. The strongest association marker with ESRD was located in ZMIZ1 (MIZ-type containing 1) and MSC (musculin). A weaker association with IRS2, TMPO, BID, KLRA1 a, ELMO1 and CNDP1 genes was also observed. Compared to the previous GoKinD study [1], results from the study by Craig et al. [6] showed little overlap in associated SNPs, which is probably due to the differences in experimental design and the ethnicity between these two studies. Craig et al. only analyzed Caucasian individuals, while the previous study included all individuals of multiple ethnicities.

ERBB4/AFF3/RGMA/MCTP2: The Genetics of Nephropathy: An International Effort (GENIE) consortium performed a meta-analysis of GWAS of three existing cohorts: GoKinD, UK-ROI (All Ireland Warren 3 Genetics of Kidneys in Diabetes UK Collection) and FinnDiane (Finnish Diabetic Nephropathy Study) [7]. The study identified risk SNPs associated with primary DN phenotype and established ESRD. A SNP in the intronic region of ERBB4 $\left(\mathrm{p}=2.1 \times 10^{-7}\right)$ was the top candidate associated with primary DN. Two SNPs associated with ESRD were also revealed. The strongest genetic association with established ESRD was a SNP residing between RGMA (RGM domain family, member A) and MCTP2 (multiple $\mathrm{C} 2$ domains, transmembrane 2; $\left.\mathrm{p}=2.0 \times 10^{-9}\right)$. Another linked SNP was located in AFF3 (AF4/FMR2 member 3; $\left.\mathrm{p}=1.2 \times 10^{-8}\right)$. AFF3 expression was upregulated by TGF- $\beta 1$ in renal epithelial cells, and knockdown of AFF3 by siRNA decreased TGF- $\beta 1$-induced profibrosis gene expression. These data indicate a role of AFF3 in renal fibrosis.

SORBS1: Population-attributable risks of SNPs for DN in GENIE database range from 0.5 to $10.5 \%$ [7]. Using the latest 1000 Genomes imputation techniques, a multi-stage GWAS was conducted to find out novel gene(s) associated with type $1 \mathrm{DN}$ (T1DN) in patients of European Ancestry [8]. SORBS1 (sorbin and SH3 domain-containing protein 1) was identified to have a strong association with T1DN in the discovery analysis after comparison to the GokinD database. However, no association was observed after comparison to the UKROI and FinnDiane databases. Its mRNA expression was inversely correlated with estimated glomerular filtration rate. The population-attributable risk of SORBS1 for DN is about $12 \%$.
SP3: It has long been known that gender is a risk factor involved in T1DN [9]. A GWAS analysis of T1DN based on gender identified two nearby SNPs with high linkage disequilibrium on chromosome $2 \mathrm{q} 31.1$, located in an intergenic region between $C D C A 7$ and $S P 3$, which are highly correlated with T1DN in women but not in men. This gender-specific association at rs4972593 was replicated in the GENIE database, and no other SNPs, including those previously reported in GENIE [6], were found to be linked to $\mathrm{DN}$ in women. The minor A allele of this SNP abolishes several transcription factor binding sites (TFBS). However, expression quantitative trait loci analysis found no significant association between the SNP and the expression level of genes within a $1-\mathrm{Mbp}$ region up- or downstream of the SNP in human HapMap3 lymphoblastoid cell line. SP3 is highly expressed in the glomeruli of women [10], compared to those of men, while CDCA7 has not so far been reported to be expressed in glomeruli. SP3 encodes a transcription factor Sp3, which directly interacts with estrogen receptor- $\alpha($ ER- $\alpha)$. Target genes of the ER- $\alpha / S p 3$ pathway include VEGFA, TGFB1, $C O L 1 A 1, N O T C H$ and $C D 2 A P$, which are all involved in the pathogenesis of DN. The fact that this SNP is not associated with DN in men may explain why it was not detected in the previous gender-mixed GWAS.

\section{Type 2 Diabetes}

ELMO1: The first GWAS for DN revealed ELMO1 (engulfment and motility protein 1 ) as a gene conferring susceptibility for type $2 \mathrm{DN}$ (T2DN) in Japanese patients [11]. The genetic association of ELMO1 with T1DN [12] in EAs and with T2DN [13] in African-Americans (AAs) has been confirmed. ELMO1 is weakly detectable in podocytes and tubular epithelial cells in normal kidneys and remarkably elevated in diabetic kidneys and in COS cells treated with high glucose. ELMO1 enhances the expression of extracellular matrix protein genes (COL1A1, $M M P 2$ and FN1) in COS cells in a TGF- $\beta$-independent manner.

PVT1: A high-density GWAS using a pooled DNA design identified PVT1 (plasmacytoma variant translocation gene 1 ) as a candidate susceptibility gene for T2DN in Pima Indians [14]. PVT1 was upregulated in mesangial cells after high glucose stimulation, and PVT1 knockdown significantly decreased extracellular matrix (ECM) molecules at both RNA and protein levels, suggesting a role of PVT1 in ECM accumulation in DN [15].

MYH9/APOL1/LIMK2 and SFI1: The MYH9 (myosin, heavy chain 9)/APOL1 (apolipoprotein L1) locus was initially found to be associated to FSGS and non-DN in two 
GWAS $[16,17]$, but not in the DN population. However, a high-density GWAS found evidence of a MYH9 association with T2DN in AAs, and the association was reproduced in a candidate gene study [18]. A finer mapping of genes susceptible for T2DN in AAs by a GWAS from the same group also revealed the association of $M H Y 9 /$ APOL1 locus [19]. The MYH9/APOL1 locus was also linked to T2DN in a family linkage study [20]. The function of MYH9/APOL1 in DN is rapidly evolving and remains a hot topic of debate. Interestingly, in T2D AAs without $\mathrm{DN}, A P O L 1$ nephropathy risk variants are protective, as evidenced by the negative association between APOL1 nephropathy risk variants and subclinical atherosclerosis and death risk [21]. In the extended study [19], several SNPs in LIMK2 (LIM domain kinase 2) and SFI1 [Sfil homolog, spindle assembly-associated (yeast) region] were associated with T2DN in AAs.

\section{Type 1 and 2 Diabetes}

Results from genetic association studies for DN are remarkably inconsistent due to the small sample size, limited power, and sparseness of data. A meta-analysis collected 153 genetic mapping studies for established DN of both T1DM and T2DM that were published in April 2010 [22]. Associated genetic variants that occurred more than once were further analyzed. A total of 24 genetic variants in or near 16 genes were finally identified. ACE (reninangiotensin system), $A K R 1 B 1$ (polyol pathway), $A P O E$ and $A P O C 1$ (lipid metabolism), VEGFA and EPO (angiogenesis), NOS3 (oxidative stress), HSPG2 (maintaining glomerular basement membrane electrostatic charge), GREM1 (cell growth and differentiation), UNC13B (apoptosis) and FRMD3, CARS, CPVL/CHN2 were associated with DN, while ELMO3 (Asians), CCR5 (Asians) and CNDP1 (type 2 diabetes) were associated with $\mathrm{DN}$ only in a subgroup. This large meta-analysis provides some novel biological insight. Pathways including reninangiotensin, angiogenesis, polyol pathway and oxidative stress are involved in $\mathrm{DN}$, as expected. Of special interest is the involvement of lipid metabolism in DN. Type 2 diabetes causes obvious dyslipidemia, and it has been recently shown that sera in patients with diabetic kidney disease impaire cholesterol efflux in podocytes [23]. The exact role of lipid metabolism in DN needs to be further investigated.

An overview of all genetic variants of genes involved in inflammatory cytokines and angiogenesis pathways in $\mathrm{DN}$ has recently been published [24]. Eleven genetic variants within or near 9 genes were found to be significantly associated with DN. VEGFA, CCR5, CCL2, IL-1, MMP9,

Genetics and Epigenetics of Diabetic

Nephropathy
$E P O, A D I P O Q$ and $I L-8$ showed increased risk for $\mathrm{DN}$, and rs1800871 (T) variant in $I L-10$ showed protective effect for DN. Enrichment analysis of these DN-associated genes revealed three functional pathways: $G$ protein-coupled receptor signaling pathways (IL-10, VEGFA, EPO, $I L-1$ and $I L-8$ ), receptor binding pathways (VEGFA, EPO, $I L-1, I L-8, I L-10, A D I P O Q$ and CCL2), and those related to chronic kidney failure (IL-6, EPO, ADIPOQ, and CCR2). The association of APOE and ENOS with DN is summarized in another meta-analysis [25].

\section{From SNP to Outcome}

A list of genetic variants has been generated in the past decade. With the rapid development of next-generation sequencing methods, one can expect novel variants to be identified. How genetic variants function in DN largely remains to be elucidated. Above $85 \%$ of disease-associated SNPs are located in noncoding regions of genome [26], including promoters and enhancers. It is deducible that SNPs are able to regulate gene expressions through establishing or abolishing TFBS. An interesting study [27] attempted to establish a mechanistic link between a noncoding SNP and clinical outcome using an integrative approach. The authors selected to investigate the function of a SNP in the promoter of FRMD3. Repression in FRMD3 on the RNA level was found in the kidney of T2DM patients. They then generated a list of genes that coexpressed with FRMD3 based on the assumption that coexpressed genes may share a 'common regulatory element'. The top pathway enriched by these coexpressed genes was the bone morphogenetic protein (BMP) signaling pathway, a part of the TGF- $\beta$ superfamily. The rs 1888747 risk allele $(G)$ created a TFBS that is believed to be inhibitory. Further analysis revealed a common TFBS module in the promoter shared among FRMD3 with the risk allele and some BMP pathway members. A testable hypothesis was proposed: SNP rs1888747 in the FRMD3 promoter region could downregulate FRMD3 expression, which subsequently abolishes stimulatory effect of FRMD3 on BMP, leading to a reduction of BMPmediated renal protection in the kidney of diabetic patients with this risk SNP. This study provides a novel strategy to test how a SNP influences the risk of a certain disease. In addition, most genetic variants associated with $\mathrm{DN}$ have a relatively low $\mathrm{OR}(<2)$, while the major risk variants have not been identified for $\mathrm{DN}$. The significance of these small-risk variants in the development and progression of DN remains unknown. DN could be caused by the additive or synergic effects of these multiple smallrisk variants. However, the ongoing studies with larger 
patient populations are needed to further identify major but rare variants for DN. In addition, genetics studies using better defined patient populations, such as patients with progressive $\mathrm{DN}$, will be helpful in identifying genes associated with a more defined disease phenotype.

\section{Epigenetics}

Other than qualitative and quantitative control of gene function by genetic variants, epigenetic control of gene regulation provides an extra layer of regulation of genes involved in the pathogenesis of DN. Rapid advances in high-throughput genome-wide profiling and sequencing methods make it feasible to scan epigenetic modification of whole genome, so-called 'epigenome-wide association studies' (EWAS), which is a strong complementarity to GWAS. In this review, we discuss the role of three types of epigenetic modification in DN: DNA methylation, miRNA, and histone modification. The epigenetic modification profile combined with the gene expression profile may provide additional information on the gene regulation in the context of DN.

\section{DNA Methylation}

DNA methylation occurs through a covalent addition of a methyl group to $5^{\prime}$-cytosines of $\mathrm{CpG}$ dinucleotides, which often cluster at the promoter region, known as $\mathrm{CpG}$ islands. This modification within the promoter usually represses gene expression through either directly disrupting the binding of transcription machinery to the promoter or indirectly recruiting corepressors to the promoter via methyl-binding proteins that recognize $5^{\prime}$-methylcytosine. Hyperglycemia has been reported to change DNA methylation [28], indicating a role of aberrant DNA methylation in DN. It has been believed that DNA methylation is very tissue specific. However, recent evidence suggests that DNA methylation patterns vary only slightly among different tissues [29]. Therefore, DNA methylation profiling obtained from surrogate tissues, such as peripheral blood cells and saliva (providing ease of collecting DNA samples) is still informative.

One study utilized the Ilumina Infinum Human Methylation27 BeadChip DNA methylation array to investigate the methylation of $\mathrm{CpG}$ islands in promoter regions across the whole genome using DNA from peripheral blood cells of T1DM patients with or without kidney disease [30]. The study revealed hypermethylation at $5^{\prime}$ of the UNC13B gene, in which a genetic variant was identified to be associated with $\mathrm{DN}[22,31]$. However, this gene, instead of suppression, was upregulated in cultured rat meningeal cells under a high glucose condition [32]. The discrepancy suggests the complexity of gene regulation, and that hypermethylation of a gene may not necessarily be associated with inhibition of its expression. Another study, using the same array as above [30], identified 187 genes that show differential site-specific DNA methylation in DNA extracted from the saliva of predominantly T2DM patients with or without ESRD [33]. The largestscale EWAS [34] thus far examined nearly half a million unique methylation sites in blood cells of 255 patients with chronic kidney disease (113 due to T1DM) and 152 control individuals (113 with T1DM without kidney disease). Twenty-three genes had a significant difference in DNA methylation between case and control groups. Six candidate genes identified were known to be involved in kidney disease, including CUX1, ELMO1, FKBP5, INH$B A-A S 1, P T P R N 2$ and PRKAG2. Among these 6 genes, there was a slight difference in ELMO1 and PRKAG2 mRNA levels in peripheral blood cells between patients with chronic kidney disease and controls. Another study analyzed DNA methylation in kidney tubular epithelial cells [35] and showed significant differences of methylation in 1,061 genes in DN patients compared to controls. Differentially methylated loci were mainly located to enhancer regions and TFBS. Of all genes with differential DNA methylation in the proximity, about $40 \%$ were correlatively regulated. There is very little overlap of genes with differential DNA methylation among the above studies, indicating that aberrant DNA methylation profiles under disease conditions are more tissue-specific than those observed in normal tissues.

Studies from animal models of kidney disease also revealed alteration of DNA methylation. It was reported that DNA hypermethylation was observed in the promoter of RASAL1, leading to a decrease in RASAL1 transcript in primary fibroblasts isolated from fibrotic versus nonfibrotic kidneys [36]. Decrease of RASAL1 enhanced Ras activity, leading to kidney fibrosis. However, RASAL1 is not on the list of aberrantly methylated genes identified from human samples.

\section{miRNA}

miRNAs are small single-stranded non-coding RNAs containing $\sim 22$ nucleotides that modulate the expression of genes by perfect or imperfect complement, leading to mRNA degradation or translation termination. miRNA typically binds to the $3^{\prime}$ untranslated region of target mRNA, but it has also been shown to bind to $5^{\prime}$ untranslated regions to inhibit translation [37]. One miRNA tar- 
gets many genes, due to its imperfect complement binding. In humans, more than 2,500 mature miRNAs are identified and regulate at least $60 \%$ of protein-coding genes [38]. miRNAs in intergenic sequences or on the antisense strand of genes are expressed quite independently, while intronic miRNAs are coordinately expressed with their host gene. miRNAs modulate multiple cell processes, and aberrant miRNA expression plays a role in the pathogenesis of various diseases. In kidneys, podocytespecific deletion of Dicer, a key enzyme for the biogenesis of MiRNAs, was shown to cause kidney failure and early death [39]. Many miRNAs involved in DN have been identified [40]. Dysregulated miRNAs are mainly involved in kidney fibrosis through regulation of ECM accumulation, a pathological hallmark of DN. The TGF- $\beta 1$ pathway is a master regulator of renal fibrosis. As such, many miRNAs have been shown to regulate the TGF- $\beta 1$ pathway or to be regulated by TGF- $\beta 1$. miRNAs function as upstream regulators of TGF- $\beta 1$ include miR-192, miR200b/c, miR-21 and miR-1207-5p. Downstream effectors of TGF- $\beta 1$ include miR-21 and miR-192. miR-192 is among the best studied miRNA in DN. However, the results on miR-192 expression in diabetic kidney are conflicting. Kato et al. [41] found a significantly higher level of miR-192 in the glomeruli of streptozotocin (STZ)-induced and $d b / d b$ diabetic mice. However, another group found a reduction in miR-192 in the cortex of diabetic $A p o E$ knockout mice [42]. In patients with established $\mathrm{DN}$, miR-192 level is lower in the kidney, and a reduced level of miR-192 correlates with tubulointerstitial fibrosis and a decline of estimated glomerular filtration rate [43]. miR-192 was shown to upregulate TGF- $\beta 1$ promoter activity in mouse mesangial cells, and inhibition of miR-192 by locked nucleic acids (LNA)-modified antisense miR192 (LNA-antimiR-192) decreased TGF- $\beta 1$ mRNA in mouse mesangial cells and the mouse kidney cortex [44]. Reciprocally, TGF- $\beta 1$ is reported to either decrease [42] or increase [45] miR-192 expression in different cell culture models. miR-192 decreases Sip1 (also called ZEB2), an E-box repressor, by directly binding to its $3^{\prime}$ UTR. Decreased Sip1 relieves the repression of Col1 a2, causing an increase in expression of Col1a2, a key gene associated with the pathogenesis of DN [41]. In STZ-induced diabetic mice, LNA-antimiR-192 decreased the miR-192 level in the kidney, restored the miRNA-192-mediated inhibition of $Z E B 1 / 2$, decreased the gene expression of collagen, TGF- $\beta 1$, and fibronectin, and ameliorated DN in vivo [46]. The discrepancy of the findings on miRNA-192 in DN among different studies could be attributed to different cell types, animal models and disease stages.

Genetics and Epigenetics of Diabetic Nephropathy

\section{Histone Modification}

PTMs of histone, mostly in the exposed amino-terminal tails, regulate gene expression by changing the chromatin structure. Important PTMs of histone include methylation, acetylation and phosphorylation. PTMs are mediated by specific enzymes. Lysine acetylation is catalyzed by histone aceyltransferases such as p300 and CBP and lysine deacetylation by HDACs. HDACs are divided into four classes: classes I, II and IV are zinc-dependent enzymes, whereas class III HDACs, sirtuins, are nicotinamide adenine dinucleotide (NAD)-dependent enzymes. Lysine methylation is carried out by lysine methyl transferases (HMTs) and demethylation by lysine demethylases (HDMs). Some PTMs of histones are considered to be transcriptional active marks including $\mathrm{H} 3 \mathrm{~K} 9 \mathrm{ac}$, $\mathrm{H} 3 \mathrm{~K} 14 \mathrm{ac}$ and $\mathrm{H} 4 \mathrm{~K} 5 \mathrm{ac}$, and $\mathrm{H} 3 \mathrm{~K} 4 \mathrm{me} 2 / 3$, while others are associated with transcriptional repression including $\mathrm{H} 3 \mathrm{~K} 9 \mathrm{me} 2 / 3$ and H3K27me3. The role of histone PTMs in $\mathrm{DN}$ has been investigated in vitro and in vivo. TGF- $\beta 1$ stimulation in rat mesangial cells upregulates the expression of fibrotic genes, such as Col1a1, CTGF, and PAI-1, correlated with deduced association of $\mathrm{H} 3 \mathrm{~K} 9 \mathrm{me} 2$ and $\mathrm{H} 3 \mathrm{~K} 9 \mathrm{me} 3$ (repressive mark) and increased association of $\mathrm{H} 3 \mathrm{~K} 4 \mathrm{me}$ (active mark) in their respective promoters [47]. SET domain-containing 7 (SET7), a H3K4 monomethyltransferase, was found to be upregulated by TGF- $\beta 1$ and recruited to the promoter of these genes. High glucose also induced the expression of these genes which were associated with similar changes in histone modification at their promoters. These changes were abolished by a TGF- $\beta 1$-specific antibody, indicating that these are TGF- $\beta 1$-mediated effects. In another study using rat mesangial cells, TGF- $\beta 1$ treatment enhanced mRNA levels of PAI-1 and p21 as well as increased the occupancy of $\mathrm{H} 3 \mathrm{~K} 9 / 14 \mathrm{ac}$ and $\mathrm{CBP} / \mathrm{p} 300$ at their promoters [48]. HDAC inhibitor also increased the expression of these genes through increasing binding of $\mathrm{H} 3 \mathrm{~K} 9 / 14 \mathrm{ac}$ at their promoters. These in vitro studies clearly demonstrate that histone modification is a key regulator of gene expression in kidney cells. In addition, hyperglycemia also increased mRNA levels of PAI-1 and p21 by increasing $\mathrm{H} 3 \mathrm{~K} 9 / 14 \mathrm{ac}$ recruitment at their promoter in glomeruli of STZ-induced diabetic mice [48]. Another in vivo study reported that high glucose inhibited DNA methylation and increased $\mathrm{H} 3 \mathrm{~K} 9 \mathrm{ac}$ at the promoter of the redoxregulating protein p66 (shc) and thereby upregulated p66shc expression in diabetic murine kidney [49]. One report studied upregulated genes implicated in DN and found increased RNA polymerase II recruitment, an increased $\mathrm{H} 3 \mathrm{~K} 4 \mathrm{me}$ level but decreased $\mathrm{H} 3 \mathrm{~K} 27 \mathrm{me} 3 \mathrm{lev}$ - 


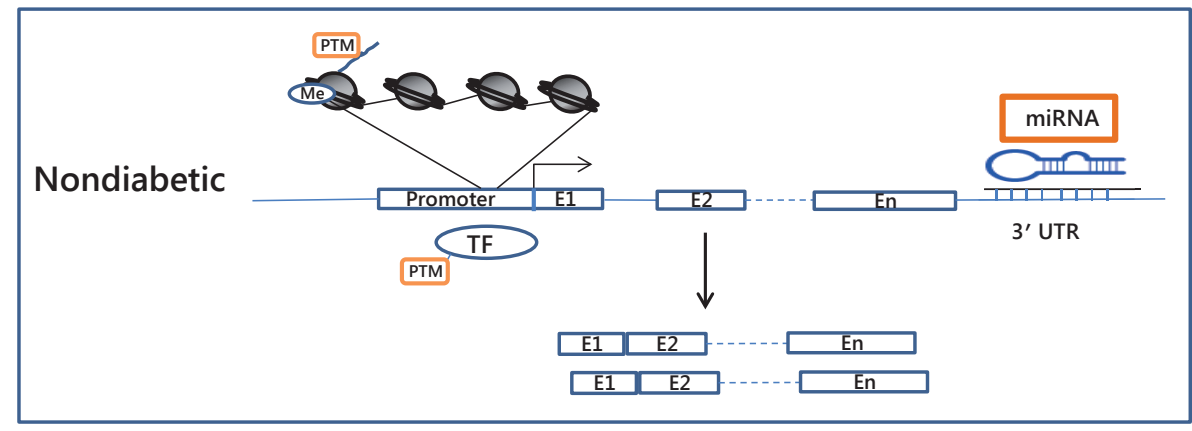

Fig. 1. Epigenetic regulation of genes in DN. The schema summarizes the epigenetic regulation of gene expression in DN. In the normal kidney, gene expression is regulated at the epigenetic level by PTMs of histone and transcription factor, DNA methylation, and miRNA. In the diabetic kidney, these epigenetic modifications are altered, leading to abnormal gene expression and DN.

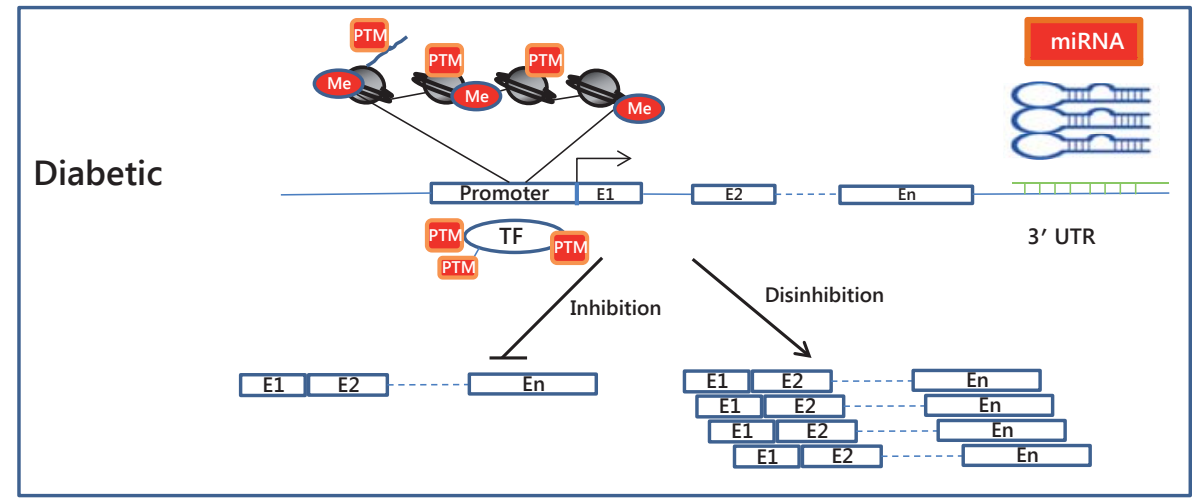

els at their respective promoters [50]. One in vivo study used microplate-based chromatin immunoprecipitation method (Matrix ChIP) to screen histone PTMs at promoters of genes encoding MCP-1, receptor for AGEs (RAGE), and PAI-1. The authors found that the increased expression of these genes was associated with higher RNA polymerase II recruitment, active marks and less repressive marks at their promoters in glomeruli of diabetic $d b$ / $d b$ mice compared to nondiabetic $d b / m$ mice [51]. Losartan, an angiotensin II type 1 receptor blocker, mitigated DN by partially reversing histone PTMs at their promoters.

Another interesting finding from a clinical trial by Miao et al. [52] suggests a potential epigenetic factor in DN. Patients with T1DM who initially received conventional therapy followed by intensive treatment had higher risks of developing diabetic complications, including DN, than those who received intensive treatment at all time, indicative of 'metabolic memory'. In order to investigate the underlying mechanisms, the authors, using chromatin immunoprecipitation, profiled H3K9Ac, H3K4Me3, and $\mathrm{H} 3 \mathrm{~K} 9 \mathrm{Me} 2$ in promoters in monocytes and lymphocytes from two groups of T1DM patients treated with either conventional or intensive therapy. Only H3K9Ac in monocytes was significantly different between the two groups. Pathway analysis using genes with hyperacety- lated promoters showed enrichment in the inflammatory pathway. In addition, a strong association between monocyte $\mathrm{H} 3 \mathrm{~K} 9 \mathrm{ac}$ and the mean $\mathrm{HbA1c}$ level was also observed. This study indicates that enriched $\mathrm{H} 3 \mathrm{~K} 9 \mathrm{ac}$ at promoters of inflammatory genes could persistently induce inflammation and diabetic complications. The combination of the $\mathrm{H} 3 \mathrm{~K} 9 \mathrm{ac}$ profile and relevant gene expression level in blood cells might provide a more complete view about the epigenetic mechanism of metabolic memory.

\section{Epigenetics - Adapting to the Environment and Entangling Together}

Genetic variants are doomed to be unchangeable. However, cells use epigenetic mechanisms to respond and adapt to the environment. Hyperglycemia puts cells in an environment of 'extra-nutrient' and pushes cells to activate three nutrient-sensing pathways: the mammalian target of rapamycin (mTOR), AMP-activated protein kinase (AMPK) and NAD-dependent histone deacetylase (Sirt1) [53]. mTOR is activated by hyperglycemia, and AMPK and Sirtl expression is decreased by hyperglycemia. These three pathways are deeply involved in DN. mTOR effects histone phosphorylation by its downstream, H3S10-specific kinase. AMPK is able to phosphorylate histone H2B serine 36. Sirt1 deacetylates histones and non-histone proteins, such as DNA methyl- 
transferase 1(DNMT1) [54], to regulateDNA methylation. Histone modifications and DNA methylation could regulate miRNA expression, and miRNAs could in turn regulate histone modification and DNA methylation. For example, miR-29a/b, which is downregulated in diabetes, directly targets $D N M T 3 A / 3 B$ [55], thereby influencing DNA methylation. miRNA-195, which is upregulated in diabetes, targets Sirt1 [56], thereby changing histone acetylation. Epigenetic changes form a network to regulate genes involved in the pathogenesis of DN (fig. 1).

\section{PTMs of Transcription Factors}

In addition to genetic variants and epigenetic modifications, gene expression regulation may be achieved by direct PTMs of transcription factors and cofactors. It is known that multiple transcription factors are activated not only by protein phosphorylation, but also by protein acetylation, such as NF- $\kappa B$ [57], Stat3 [58], and p53 [59]. Systems biology analysis of human diabetic kidneys suggests that NF- $\mathrm{KB}$ and Stat3 are key transcription factors involved in $\mathrm{DN}$ through activation of downstream proinflammatory gene expression [60]. We have recently shown that acetylation of NF- $\mathrm{BB}$ and Stat 3 is increased in diabetic kidneys, leading to their activation [61]. In addition, acetylation of NF- $\kappa B$ and Stat 3 is negatively regulated by Sirt1. Knockdown of Sirt1 in podocytes aggravates inflammation and kidney injury, while inhibition of NF- $\kappa \mathrm{B}$ acetylation by using a specific bromodomain inhibitor attenuates inflammation and kidney injury in diabetic mice.

\section{Concluding Remarks}

Rapid developments of high-throughput genomewide screening techniques have greatly broadened our understanding of genetic and epigenetic changes in disease such as DN. Many genetic studies have been performed in DN, including large studies such as FIND and GoKinD studies. However, although multiple genes and loci have been found to be associated with $\mathrm{DN}$, none of them have a major impact. A better designed study, with a larger sample size and a better defined patient population may help to identify key genes involved in DN. In addition, epigenetic changes including DNA methylation, histone modification, and miRNA regulation also play a major role in the pathogenesis of DN. However, epigenetic study is limited in human kidney disease because of the limited availability of samples and the heterogeneity of kidney tissues with multiple cells. Due to these limitations and the poor differentiation status of cultured kidney cells, recent epigenetic data generated are not consistent among different studies. These technical limitations need to be overcome to generate more solid data on epigenetic changes in $\mathrm{DN}$, so that they can be used as potential biomarkers and drug target for DN.

\section{Disclosure Statement}

The authors have no conflicts of interest to declare.

\section{References}

1 Bakris GL, Williams M, Dworkin L, et al: Preserving renal function in adults with hypertension and diabetes: a consensus approach. National Kidney Foundation Hypertension and Diabetes Executive Committees Working Group. Am J Kidney Dis 2000;36:646-661.

-2 Seaquist ER, Goetz FC, Rich S, Barbosa J: Familial clustering of diabetic kidney disease. Evidence for genetic susceptibility to diabetic nephropathy. N Engl J Med 1989;320:11611165.

3 Pezzolesi MG, Poznik GD, Mychaleckyj JC, Paterson AD, Barati MT, Klein JB, Ng DP, Placha G, Canani LH, Boright AP, Bull SB; DCCT/EDIC Research Group, Doria A, Rogus JJ, Rich SS, Warram JH, Krolewski AS: Genome-wide associations scan for diabetic nephropathy susceptibility genes in type $1 \mathrm{di}$ abetes. Diabetes 2009;58:1403-1410.

4 Maeda S, Araki S, Babazono T, Toyoda M, Umezono T, Nakamura Y: Replication study for the association between four loci Identified by a genome-wide association study on European American subjects with type 1 diabetes and susceptibility to diabetic nephropathy in Japanese subjects with type 2 diabetes. Diabetes 2010;59:2075-2079.

5 Pezzolesi MG, Poznik GD, Skupien J, Smiles AM, Mychaleckyj JC, Rich SS, Warram JH, Krolewski AS: An intergenic region on chromosome $13 \mathrm{q} 33.3$ is associated with the susceptibility to kidney disease in type 1 and 2 diabetes. Kidney Int 2011;80:105-111.

6 Craig DW, Millis MP, DiStefano JK: Genomewide SNP genotyping study using pooled DNA to identify candidate markers mediating susceptibility to end-stage renal disease attributed to Type 1 diabetes. Diabet Med 2009;26:1090-1098.

7 Sandholm N, Salem RM, Maxwell AP: New susceptibility loci associated with kidney disease in type 1 diabetes. PLoS Genet 2012;8:e1002921.
-8 Germain M, Pezzolesi MG, Hadjadj S: SORBS1 gene, a new candidate for diabetic nephropathy: results from a multi-stage genome-wide association study in patients with type 1 diabetes. Diabetologia 2015;58:543548

-9 Harjutsalo V, Maric C, Forsblom C, Thorn L, Wadén J, Groop PH; FinnDiane Study Group: Sex-related differences in the long-term risk of microvascular complications by age at onset of type 1 diabetes. Diabetologia 2011;54: 1992-1999.

10 Woroniecka KI, Park AS, Mohtat D, Thomas DB, Pullman JM, Susztak K: Transcriptome analysis of human diabetic kidney disease. Diabetes 2011;60:2354-2369.

11 Maeda S, Osawa N, Hayashi T, Tsukada S, Kobayashi M, Kikkawa R: Genetic variations associated with diabetic nephropathy and type II diabetes in a Japanese population. Kidney Int Suppl 2007;106:S43-S48. 
$\checkmark 12$ Pezzolesi MG, Katavetin P, Kure M, Poznik GD, Skupien J, Mychaleckyj JC, Rich SS, Warram JH, Krolewski AS: Confirmation of genetic associations at ELMO1 in the GoKinD collection supports its role as a susceptibility gene in diabetic nephropathy. Diabetes 2009, 58:2698-2702.

$\checkmark 13$ Leak TS, Perlegas PS, Smith SG, Keene KL, Hicks PJ, Langefeld CD, Mychaleckyj JC, Rich SS, Kirk JK, Freedman BI, Bowden DW, Sale MM: Variants in intron 13 of the ELMO1 gene are associated with diabetic nephropathy in African Americans. Ann Hum Genet 2009; 73:152-159.

14 Hanson RL, Craig DW, Millis MP, Yeatts KA, Kobes S, Pearson JV, Lee AM, Knowler WC, Nelson RG, Wolford JK: Identification of PVT1 as a candidate gene for end-stage renal disease in type 2 diabetes using a pooling-based genome-wide single nucleotide polymorphism association study. Diabetes 2007;56:975-983.

15 Alvarez ML, DiStefano JK: Functional characterization of the plasmacytoma variant translocation 1 gene (PVT1) in diabetic nephropathy. PLoS One 2011 22;6:e18671.

16 Kopp JB, Smith MW, Nelson GW, Johnson RC, Freedman BI, Bowden DW, Oleksyk T, McKenzie LM, Kajiyama H, Ahuja TS, Berns JS, Briggs W, Cho ME, Dart RA, Kimmel PL, Korbet SM, Michel DM, Mokrzycki MH, Schelling JR, Simon E, Trachtman H, Vlahov D, Winkler CA: MYH9 is a major-effect risk gene for focal segmental glomerulosclerosis. Nat Genet 2008;40:1175-1184

$\checkmark 17$ Kao WH, Klag MJ, Meoni LA, Reich D, Berthier-Schaad Y, Li M, Coresh J, Winkler CA, Smith MW, Parekh RS; Family Investigation of Nephropathy and Diabetes Research Group: MYH9 is associated with nondiabetic end-stage renal disease in African Americans. Nat Genet 2008;40:1185-1192.

- 18 McDonough CW, Palmer ND, Hicks PJ, Roh BH, An SS, Cooke JN, Hester JM, Wing MR, Bostrom MA, Rudock ME, Lewis JP, Talbert ME, Blevins RA, Lu L, Ng MC, Sale MM, Divers J, Langefeld CD, Freedman BI, Bowden DW: A genome-wide association study for diabetic nephropathy genes in African Americans. Kidney Int 2011;79:563-572.

- 19 Palmer ND, Ng MC, Hicks PJ, Mudgal P, Langefeld CD, Freedman BI, Bowden DW: Evaluation of candidate nephropathy susceptibility genes in a genome-wide association study of African American diabetic kidney disease. PLoS One 2014;9:e88273.

-20 Igo RP Jr, Iyengar SK, Nicholas SB, Goddard KA, Langefeld CD, Hanson RL, Duggirala R, Divers J, Freedman BI; Family Investigation of Nephropathy and Diabetes Research Group: Genomewide linkage scan for diabetic renal failure and albuminuria: the FIND study. Am J Nephrol 2011;33:381-389.

$\checkmark 21$ Freedman BI, Langefeld CD, Lu L, et al: APOL1 associations with nephropathy, atherosclerosis, and all-cause mortality in African Americans with type 2 diabetes. Kidney Int 2015;87:176-181.
22 Mooyaart AL, Valk EJ, van Es LA, Bruijn JA, de Heer E, Freedman BI, Dekkers OM, Baelde HJ: Genetic associations in diabetic nephropathy: a meta-analysis. Diabetologia 2011;54: 803-811.

23 Merscher-Gomez S, Guzman J, Burke GW 3rd, Fornoni A; FinnDiane Study Group: Cyclodextrin protects podocytes in diabetic kidney disease. Diabetes 2013;62:3817-3827.

24 Nazir N, Siddiqui K, Al-Qasim S, Al-Naqeb D: Meta-analysis of diabetic nephropathy associated genetic variants in inflammation and angiogenesis involved in different biochemical pathways. BMC Med Genet 2014;15:103.

25 Smyth LJ, Duffy S, Maxwell AP, McKnight AJ: Genetic and epigenetic factors influencing chronic kidney disease. Am J Physiol Renal Physiol 2014;307:F757-F776.

26 Maurano MT, Humbert R, Kaul R, Stamatoyannopoulos JA: Systematic localization of common disease-associated variation in regulatory DNA. Science 2012;337:1190-1195.

27 Martini S, Nair V, Patel SR, Eichinger F, Nelson RG, Weil EJ, Pezzolesi MG, Krolewski AS Randolph A, Keller BJ, Werner T, Kretzler M: From single nucleotide polymorphism to transcriptional mechanism: a model for FRMD3 in diabetic nephropathy. Diabetes 2013;62:2605-2612.

28 Barrès R, Osler ME, Zierath JR: Non-CpG methylation of the PGC-1alpha promoter through DNMT3B controls mitochondrial density. Cell Metab 2009;10:189-198.

29 Rakyan VK, Down TA, Thorne NP, et al: An integrated resource for genome-wide identification and analysis of human tissue-specific differentially methylated regions (tDMRs). Genome Res 2008;18:1518-1529.

30 Bell CG, Teschendorff AE, Rakyan VK, Maxwell AP, Beck S, Savage DA: Genome-wide DNA methylation analysis for diabetic nephropathy in type 1 diabetes mellitus. BMC Med Genomics 2010;3:33.

31 Trégouet DA, Groop PH, Vionnet N; EURAGEDIC Consortium: G/T substitution in intron 1 of the UNC13B gene is associated with increased risk of nephropathy in patients with type 1 diabetes. Diabetes 2008;57:28432850.

32 Goldenberg NM, Silverman M: Rab34 and its effector munc13-2 constitute a new pathway modulating protein secretion in the cellular response to hyperglycemia. Am J Physiol Cell Physiol 2009;297:C1053-C1058.

-33 Sapienza C, Lee J, Powell J, Erinle O, Yafai F, Reichert J, Siraj ES, Madaio M: DNA methylation profiling identifies epigenetic differences between diabetes patients with ESRD and diabetes patients without nephropathy. Epigenetics 2011;6:20-28.

34 Smyth LJ, McKay GJ, Maxwell AP, McKnight AJ: DNA hypermethylation and DNA hypomethylation is present at different loci in chronic kidney disease. Epigenetics 2014;9: 366-376.
35 Ko YA, Greally JM, Susztak K: Cytosine methylation changes in enhancer regions of core pro-fibrotic genes characterize kidney fibrosis development. Genome Biol 2013; 14:R108.

36 Bechtel W, McGoohan S, Zeisberg EM, Müller GA, Kalbacher H, Salant DJ, Müller CA, Kalluri R, Zeisberg M: Methylation determines fibroblast activation and fibrogenesis in the kidney. Nat Med 2010;16:544-550.

37 Hausser J, Syed AP, Bilen B, Zavolan M: Analysis of CDS-located miRNA target sites suggests that they can effectively inhibit translation. Genome Res 2013;23:604-615.

38 Kozomara A, Griffiths-Jones S: miRBase: annotating high confidence microRNAs using deep sequencing data. Nucleic Acids Res 2014;42(Database issue):D68-D73.

39 Gentle ME, Shi S, Daehn I, Zhang T, Qi H, Yu L, D'Agati VD, Schlondorff DO, Bottinger EP: Podocyte-selective deletion of dicer induces proteinuria and glomerulosclerosis. J Am Soc Nephrol 2013;24:787-799.

-40 Wu H, Kong L, Zhou S, Cui W, Xu F, Luo M Li X, Tan Y, Miao L: The role of microRNAs in diabetic nephropathy. J Diabetes Res 2014; 2014:920134.

41 Kato M, Zhang J, Wang M, Lanting L, Yuan H, Rossi JJ, Natarajan R: MicroRNA-192 in diabetic kidney glomeruli and its function in TGF- $\beta$-induced collagen expression via inhibition of E-box repressors. Proc Natl Acad Sci USA 2007;104:3432-3437.

42 Wang B, Herman-Edelstein M, Koh P, et al: $\mathrm{B}$-cadherin expression is regulated by miR$192 / 215$ by a mechanism that is independent of the profibrotic effects of transforming growth factor-beta. Diabetes 2010;59:17941802.

43 Krupa A, Jenkins R, Luo DD, Lewis A, Phillips A, Fraser D: Loss of MicroRNA-192 promotes fibrogenesis in diabetic nephropathy. J Am Soc Nephrol 2010;21:438-447.

44 Kato M, Arce L, Wang M, Putta S, Lanting L, Natarajan R: A microRNA circuit mediates transforming growth factor- $\beta 1$ autoregulation in renal glomerular mesangial cells. Kidney Int 2011;80:358-368.

$\checkmark 45$ Kato M, Dang V, Wang M, et al: TGF- $\beta$ induces acetylation of chromatin and of Ets- 1 to alleviate repression of miR-192 in diabetic nephropathy. Sci Signal 2013;6:ra43.

46 Putta S, Lanting L, Sun G, Lawson G, Kato M, Natarajan R: Inhibiting microRNA-192 ameliorates renal fibrosis in diabetic nephropathy. J Am Soc Nephrol 2012;23:458-469.

47 Sun G, Reddy MA, Yuan H, Lanting L, Kato M, Natarajan R: Epigenetic histone methylation modulates fibrotic gene expression. J Am Soc Nephrol 2010;21:2069-2080.

48 Yuan H, Reddy MA, Sun G, Lanting L, Wang M, Kato M, Natarajan R: Involvement of p300/CBP and epigenetic histone acetylation in TGF- $\beta 1$-mediated gene transcription in mesangial cells. Am J Physiol Renal Physiol 2013;304:F601-F613. 
49 Bock F, Shahzad K, Wang H, Stoyanov S, Wolter J, Dong W, Pelicci PG, Kashif M, Ranjan S, Schmidt S, Ritzel R, Schwenger V, Reymann KG, Esmon CT, Madhusudhan T, Nawroth PP, Isermann B: Activated protein C ameliorates diabetic nephropathy by epigenetically inhibiting the redox enzyme p66Shc. Proc Natl Acad Sci USA 2013;110:648-653.

50 Komers R, Mar D, Denisenko O, Xu B, Oyama TT, Bomsztyk K: Epigenetic changes in renal genes dysregulated in mouse and rat models of type 1 diabetes. Lab Invest 2013;93: 543-552.

51 Reddy MA, Sumanth P, Lanting L, Yuan H, Wang M, Mar D, Alpers CE, Bomsztyk K, Natarajan R: Losartan reverses permissive epigenetic changes in renal glomeruli of diabetic $\mathrm{db} / \mathrm{db}$ mice. Kidney Int 2014;85:362-373.

52 Miao F, Chen Z, Genuth S, Paterson A, Zhang L, Wu X, Li SM, Cleary P, Riggs A, Harlan DM, Lorenzi G, Kolterman O, Sun W, Lachin
JM, Natarajan R; DCCT/EDIC Research Group: Evaluating the role of epigenetic histone modifications in the metabolic memory of type 1 diabetes. Diabetes 2014;63:17481762.

53 Kume S, Koya D, Uzu T, Maegawa H: Role of nutrient-sensing signals in the pathogenesis of diabetic nephropathy. Biomed Res Int 2014;2014:315494.

54 Peng L, Yuan Z, Ling H, et al: SIRT1 deacetylates the DNA methyltransferase 1 (DNMT1) protein and alters its activities. Mol Cell Biol 2011;31:4720-4734.

5 Fabbri M, Garzon R, Cimmino A, et al: MicroRNA-29 family reverts aberrant methylation in lung cancer by targeting DNA methyltransferases 3A and 3B. Proc Natl Acad Sci USA 2007;104:15805-15810.

56 Zhu H, Yang Y, Wang Y, Li J, Schiller PW, Peng T: MicroRNA-195 promotes palmitateinduced apoptosis in cardiomyocytes by down-regulating Sirt1. Cardiovasc Res 2011; 92:75-84.

57 Quivy V, Van Lint C: Regulation at multiple levels of NF-kappaB mediated transactivation by protein acetylation. Biochem Pharmacol 2004;68:1221-1229.

58 Yuan ZL, Guan YJ, Chatterjee D, Chin YE: Stat3 dimerization regulated by reversible acetylation of a single lysine residue. Science 2005;307:269-273.

59 Reed SM, Quelle DE: p53 acetylation: regulation and consequences. Cancers (Basel) 2014; 7:30-69.

60 Komorowsky CV, Brosius FC 3rd, Pennathur S, Kretzler M: Perspectives on systems biology applications in diabetic kidney disease. J Cardiovasc Transl Res 2012;5:491-508.

61 Liu R, Zhong Y, Li X, Chen H, Jim B, Zhou MM, Chuang PY, He JC: Role of transcription factor acetylation in diabetic kidney disease. Diabetes 2014;63:2440-2453. 